\title{
Video Chat at the Front Desk: Providing In- Person Help from a Distance
}

\author{
William Helman \\ Sara Arnold-Garza \\ Hannah Krauss \\ Jennifer Wodarczyk \\ Towson University
}

\begin{abstract}
This column describes an approach to helping patrons in the physical library through a telepresence service, while maintaining a safe environment during the COVID-19 pandemic. This video chat service was achieved using the WebEx meeting platform and an iPad, which was later upgraded to a Cisco WebEx DX80 display.
\end{abstract}

Keywords: Kiosk, Telepresence, Contactless Reference

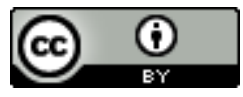

This is an Open Access article distributed under the terms of the Creative Commons Attribution 4.0 International License (http://creativecommons.org/licenses/by/4.0), which permits unrestricted use, distribution, and reproduction in any medium, provided the original work is properly cited. 
Library workers at Albert S. Cook Library at Towson University were challenged by the COVID19 pandemic to meet our mission of access and service for our patrons, while protecting the health and safety of our staff. As a small "Return to Cook" group planned in Summer 2020 for the reopening of the building to patrons in Fall 2020, most staff and student employees were working remotely, and needed to stay that way to keep building density low. We were looking for creative solutions to our empty service desks and responding to the many questions that come up while a patron visits the building.

Our first attempt to provide some level of public service support in the building, without requiring a lot of direct contact with patrons, was staffing our entrance with a greeter. Many retail organizations were using this model, and some libraries were looking to adapt it also. However, there were simply not enough library employees willing to fill this role during library open hours, which was offered on a voluntary basis, due to the potential for confrontation or conflict and the continued exposure to others. Based on this experience, we knew we could not reliably answer patron questions in person in any form in the building. We also knew that our research help services via phone, text, chat, email, and virtual meetings were robust and meeting needs for the most in-depth research questions. It was clear that what was needed was an efficient way to answer the myriad of simple questions that a patron has while they try to navigate our spaces, technologies, and resources.

The question became, "How do we extend the concept of contactless borrowing to a service desk?" A possible solution presented itself out of all the teleconference meetings, across Zoom, WebEx, and similar tools, that were becoming our new normal. Towson's enterprise WebEx platform was quickly gaining popularity within the library for both text and video collaboration. By flipping the model of a personal room, we decided to re-mix hardware the library already owned to pilot an iPad- 
based video chat kiosk. Our goal was to allow anyone to walk up to the service desk and be able to talk to an employee who may not even be in the building.

A telepresence planning group consisting of librarians and staff from the Library IT, Access Services, Research and Instruction, and Content Management departments immediately began working out both the technology and the staffing that would be required to run a contactless service desk. We met with stakeholders in the library and in the University's Central IT, brainstorming possibilities and anticipating barriers. While issues around privacy concerns, technical limitations, and scheduling came up, we also saw a great opportunity as well. We anticipated the questions that would come to the kiosk would be the kind our circulation staff and student employees were already experienced with. Staffing the kiosk could provide an opportunity for telework for many whose job descriptions typically relied entirely on their physical presence in the building.

We were aware of the barriers our patrons and staff typically encounter while using web-based solutions, including internet access, bandwidth limitations, and technology access, skill, and comfort. This perspective guided our approach to telepresence service prompting us to simplify the login process, allow staff to turn off their camera and microphone when patrons are not present, and provide quick response assistance to colleagues via WebEx when needed. Patrons benefitted from a seamless interaction similar to an in-person experience at the service desk where a staff member is available to answer questions. Limiting our telepresence to a single kiosk was necessary to make it feasible, since we had limited people available to staff the service.

\section{Technology}

We were able to quickly set up the contactless service desk pilot by re-mixing and re-using existing technologies available in the library and across the University. The following is an overview of 
the hardware, software, and methods we used, but this type of video kiosk can be replicated in any number of different ways. We will also describe other options that might be more readily available in your library.

The basic requirements for our video chat kiosk included a webcam and microphone, a video screen, a place to put them, and a means to connect them to library staff working remotely. Prior to the pandemic the library employed five iPad kiosks, on mobile stands, to manage reservations for group study rooms. These basic enclosures, widely used in retail, museum, and academic environments, provided a secure yet easily reconfigurable way to put interactive technology where it is needed. With social distancing requirements shuttering our group study spaces, though, these kiosks had been stored for the foreseeable future.

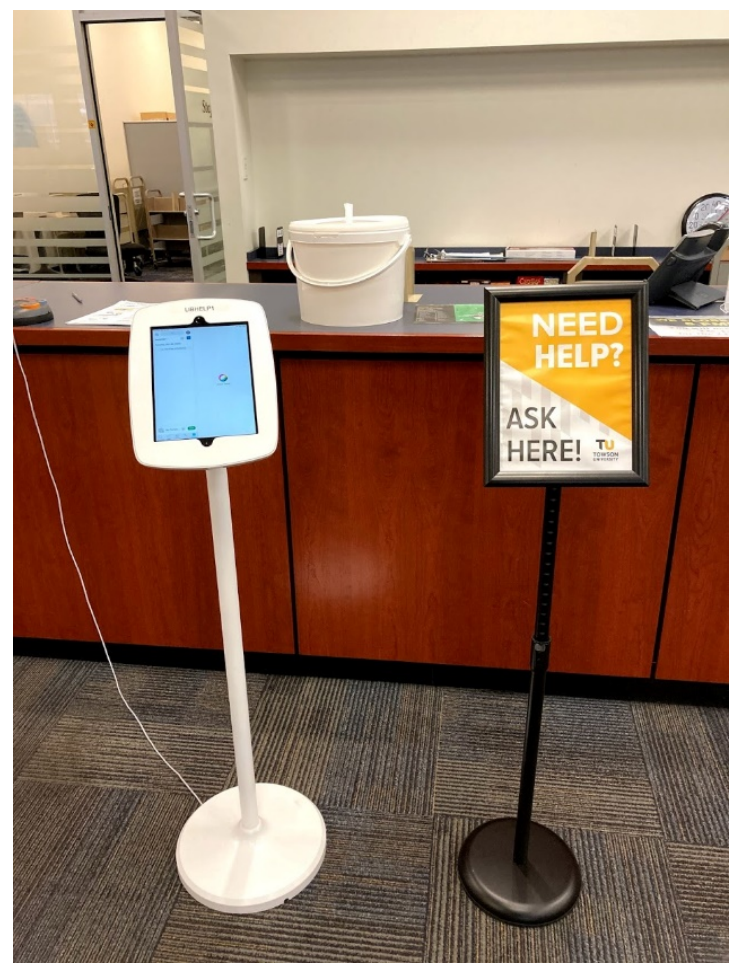

Image 1. iPad Kiosk

In early June of 2020, we realized we could use the iPad's built-in webcam and microphone to provide patrons a way to talk to staff who were working remotely (either from another room in the Journal of New Librarianship, 6(2021) pp. 49-58 10.21173/newlibs/10/6 
building, or even from home) when we opened in the fall. This contactless service desk depended on flipping the model of the personal room in popular teleconferencing tools, like WebEx or Zoom. Typically, a person opens their room and provides the address for those they would like to invite to log in to it. Here we provided an iPad kiosk where staff on premises opened a room each morning and remote staff could then access the room throughout the day from elsewhere. This gives the patron in the library the ability to walk up (on camera) to an already open video chat session and just start talking like they might at a physically staffed desk, while allowing a staffer on the other end the chance to rotate in and out of the open room based on their assigned shifts throughout the day. Then, when the conversation is done, the patron can just walk away, leaving the session open for the next person, while avoiding the need to physically interact with the kiosk.

Our partners in the University's Central IT assisted us on several key steps setting up the service. We began with installing an enterprise version of WebEx Meetings, provided by a centrally managed campus license, on a library iPad to test our service model using one of our own individual accounts. After confirming that our flipped personal room model worked, we requested that they create several service accounts we could use to open the personal rooms on three kiosks we had ready. This way on-premises staff could share the generic login information, and no individual staff member would need to tie up their own WebEx account. Apple's built in Guided Access allowed us to configure the iPad to only run WebEx, giving us peace of mind that a patron would not be able to accidentally disrupt the service.

We had success using what we had on hand, but there are many other ways you could set up a similar contactless service desk with what is available in your own library. Many institutions have easy access to webcams and recently retired PCs that could be pulled out of storage for the purpose, and 
all-in-one computers that come with built in webcams have been popular in recent years. WebEx was familiar and easily available to us, but Zoom, FaceTime, RingCentral, and other teleconference systems have similar capabilities. We used the iOS Guided Access feature to lock down our kiosk, but there are other kiosk apps for iPads, and other tablets or PCs have similar tools available.

There is also room to grow if you partner with others in your institution. As word of our contactless service desk spread across campus, others began reaching out to us to help. We were offered the chance to pilot a Cisco WebEx DX80 web conferencing kit for Central IT, as they consider campus-wide uses for the technology. The larger screen, better speakers and higher quality webcam were a welcome upgrade to our iPad kiosks. Another unit has let us borrow a Temi Personal Robot that was sitting unused in their office during our campus low density response to the pandemic. Now we are just beginning to experiment with what it might be like to have a mobile contactless service desk, piloted remotely around the library by staff working at home.

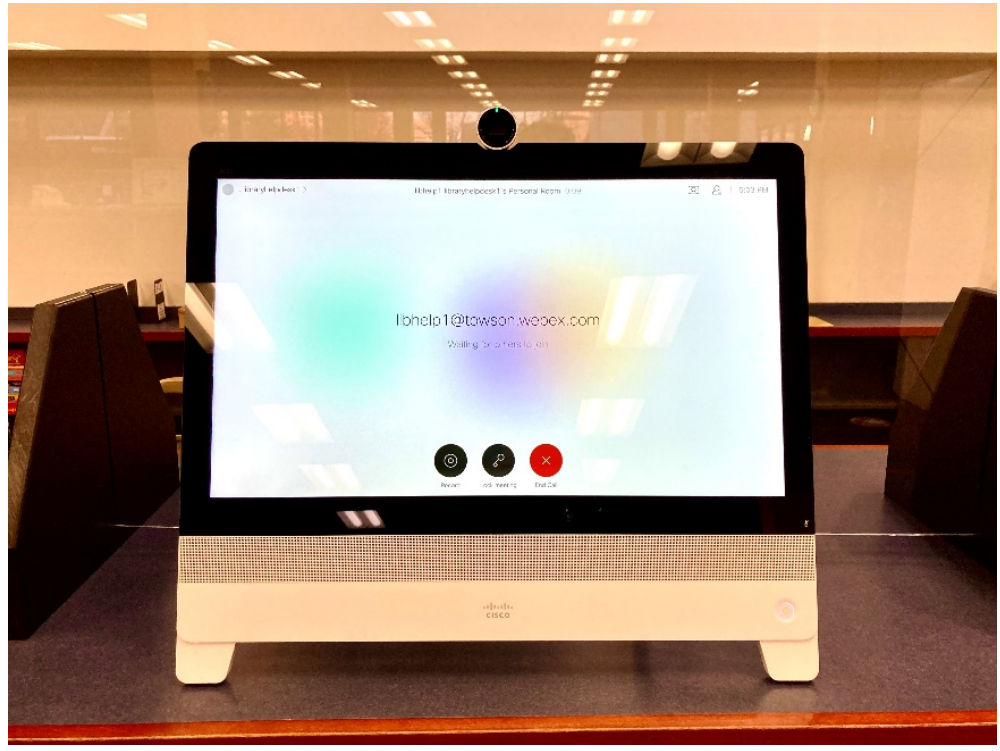

Image 2. Cisco WebEx DX80 display 


\section{Service Model}

In the first service model, the kiosk was run mostly by library staff and librarians, reflecting its role as the virtual version of the combined service desk which was staffed by circulation staff, student employees, and librarians pre-pandemic. Volunteers from different departments across the library assisted in the first days of the kiosk. As the semester continued, the staffing model shifted from primarily full-time staff to student employees. It became apparent over time that the kiosk served a distinct purpose that was complementary to the role of our already robust chat service; patrons who needed directional assistance, or general understanding of library policies were approaching the kiosk. In-depth research questions continued to come through our longstanding chat service, primarily staffed by our Research and Instruction department. A WebEx space was also created to provide additional support to those staffing the kiosk; this allowed library staff and student employees to pass along questions they didn't know an immediate answer for, just as they might have asked questions of others at the combined service desk. The ability to message others involved in running the kiosk, who come from several different library departments, allowed those staffing the kiosk to signal when inperson assistance was required, or more specialized information was sought. The WebEx space was also a way for those filling shifts to quickly notify others of any technological difficulties with the kiosk or last-minute coverage needs. This ability to instantly reach out to other staff and student employees became an essential component of the kiosk service model.

For the first few months the kiosk was placed near the end of the existing service desk, closest to the library entrance, with a sign indicating that patrons could use it to find information. There was low usage, as many patrons walked past the kiosk towards the desk in search of a person and did not 
see the signs. In response to this observation, we relocated the kiosk to be centered in front of the service desk and an additional sign was placed, in order to draw more attention to it.

Supervisors of student employees asked those who were interested in working at the kiosk to attend required trainings, which are described in more detail in the next section. Some of the students opted not to participate, feeling uncomfortable with the virtual nature of the interactions, but many, even those from departments that were not typically front facing, were eager to help with this new service. This was perhaps due to the opportunity to work remotely, which many of our student employees have expressed a preference for since the beginning of the pandemic. Staffing the kiosk provided predictable hours for student employees teleworking in various departments.

\section{Training}

In order to begin staffing the kiosk, members of the Telepresence Planning Group organized synchronous training sessions for library staff and student employees. This training was offered at two separate times to accommodate course and work schedules. Individuals who signed up were also provided with documentation about the software and staffing model before the training, in order to allow time for reflection. To streamline the login process, staff were provided direct access remotely. Topics in training included using the chat feature, screen sharing, customer service etiquette, navigating the software, troubleshooting, communicating with others staffing the service, and an open question and answer period. Student and staff employees had access to a recording of the synchronous training videos and documents for review at their convenience.

Providing training attendees an opportunity to ask questions during the synchronous training was additionally helpful to the Telepresence Planning Group, as attendees highlighted potential issues not previously identified. During the training, student comments about bandwidth limitations 
provided helpful feedback. For instance, connection stability and sound quality was notably improved when a student colleague turned off their camera. As a result of this feedback staff and student employees were directed to turn their cameras and microphones off as needed to save on bandwidth and turn their microphone on when patrons approached the kiosk. Although not everyone who staffed the kiosk was comfortable keeping their video on throughout the duration of their shift, all staff provided a profile photo or avatar that they displayed on the screen while signed in. Questions regarding health and safety arose as well, such as the proper procedure if the individual on the kiosk sees someone in the library not wearing a mask. Overall, the trainings provided learning opportunities for both the Telepresence Planning Group and those attending.

\section{Statistics}

Prior to the pandemic, a "stats tracker" was already in place to record interactions with patrons at our service desks. Student and staff employees complete the online form after assisting a patron. Towson University started the Fall 2020 semester on August 24, 2020, with about $70 \%$ of courses completely remote, and about half of the usual number of students living on campus. The pandemic clearly influenced the number of people in the physical library space including the patrons seeking assistance using the kiosk.

The contactless service desk began service as patrons were welcomed back into the library building, which opened at a reduced capacity. We rarely recorded more than 2 questions at the kiosk in a day, which is quite low compared to our pre-pandemic service desk statistics but reflects the drastically reduced number of people on campus and building capacity. We observed an increase in days with three or more transactions recorded after the Cisco WebEx DX80 replaced the less visible iPad display in October 2020, which also coincided with midterms, a traditionally busier time in the 
library. The number of questions dropped again after the Thanksgiving/Native American Heritage Day

break when the University fully transitioned to virtual courses to finish the semester. Notably, many of the transactions we would have recorded at our physical service desk before the pandemic were now taking place via traditional chat, which is counted separately from the kiosk transactions, and may also account for such low statistics. Despite continued low use of the kiosk as compared to our historic service desk statistics, we recognized the overall benefit of continuing the service, since there are no public service staff available to patrons in the building otherwise.

\section{Conclusion}

Our next steps focus on improvements for the future, and planning for anticipated challenges as the pandemic continues. We may be able to encourage more use of the kiosk by addressing two known barriers: awareness and comfort. We are currently discussing how we can make patrons in the building aware that the kiosk is available to them, beyond the signage we have used so far. We also hope to find ways to make patrons more comfortable approaching a screen, just as they would approach a person at our service desk. The start of the Spring 2021 semester brings expanded library hours, and the challenge of staffing the kiosk during evenings and weekends.

The contactless service desk was just one of the many efforts our library pursued to adapt to the changing environment during the pandemic, as was likely happening in all academic libraries throughout 2020. Our attempt to continue to provide help for patrons in the building, while protecting staff and keeping building density low, has required reflection and adjustment over time. Even though we continue to see much lower use than our public service desk did pre-pandemic, we consider the availability of the kiosk to be essential for those visiting our building and being able to offer continued work opportunities to our student and staff employees who need a remote work option is vitally 
important to our organization. Our assessment of the cost/benefit balance for this service leads us to conclude that we must keep the kiosk to meet the needs of those in the building while staffing presence is low, even if it is not a highly used service. 